\title{
VIOLÊNCIA SOCIAL, POBREZA E IDENTIDADE ENTRE JOVENS NO ENTORNO DO DISTRITO FEDERAL ${ }^{1}$
}

\author{
Marília Luíza Peluso* \\ Cassiana Vaz Tormim**
}

\section{RESUMO:}

Pretende-se, nesse artigo, trabalhar com mudanças de identidade e de comportamento observadas entre jovens sujeitos a situações de marginalidade e violência que atuam no Movimento de Jovens, da Igreja Católica, no município de Luziânia, no Entorno do Distrito Federal. Procura-se identificar como o pertencimento a um grupo religioso influencia as visões de mundo e de si mesmo e refletir sobre como a exclusão social contribui para a construção de um imaginário social que penaliza os jovens pobres. Duas hipóteses nortearam a elaboração do estudo. Primeiro, ao se modernizar um território, como ocorreu em Luziânia sob a influência de Brasília, criam-se territórios degradados de pobreza e exclusão, cujos moradores se percebem como possuidores de identidades deterioradas. Segundo, pertencer a um grupo religioso resgata o sujeito, permite o surgimento de novas sociabilidades, o que leva a mudanças de identidade e de comportamento.

\section{PALAVRAS-CHAVE:}

Identidade - religião - jovens - exclusão social - modernização territorial

\section{ABSTRACT:}

This article intends to work with the identity and the behaviour changes observed among young people under situations of marginality and violence who work at the Young Movement of the Catholic Church in the city of Luziânia - Goias, in the outskirts of the Federal District. It tries to identify how the belonging to a religious group influences the vision of the world and of one's life, in addition to how the social exclusion contributes to build a fictitious society that penalises the young poor people. Two hypotheses guided the elaboration of this study. First, when modernising a territory, as it occurred in Luziânia under the influence of Brasilia, degraded territories of poverty and exclusion are created where the inhabitants are seen as having deteriorated identities. Second, being part of a religious group may rescue the sense of citizenship and allow the sprouting of new sociability, which helps changing the behaviour and the identity.

\section{KEY WORDS:}

Identity - religion - young people - social exclusion - territorial modernisation

\section{I- Introdução}

A relação entre identidade e espaço tornou-se uma questão importante para a Geografia, desde que se procurou, como ressalta CLAVAL (2001, p.36), "esclarecer a dinâmica dos comportamentos humanos", enquanto "expressão de processos cognitivos, de atividades mentais, de trocas de informação e de idéias".(CLAVAL, 2001, p. 39). Nesse sentido, pretende-se trabalhar com as mudanças de identidade que levam a alterações do comportamento observadas entre rapazes e moças sujeitos a situações de marginalidade e violência que atuam no Movimento de Jovens 
da Igreja Católica, em Luziânia, município limítrofe ao Distrito Federal.

A pesquisa foi feita com dois grupos de jovens, cada um deles com cinco pessoas. Um deles residia no loteamento periférico do Jardim Ingá e o outro no centro de Luziânia. Na periferia as idades variavam entre 18 e 28 anos. Os mais velhos possuíam o 20 grau completo (um deles inclusive com curso técnico profissionalizante) e o mais novo ainda estava cursando. Três dos entrevistados nasceram em Brasília, um no Plano Piloto e dois em Taguatinga. Os outros dois respondentes nasceram na Paraíba. Os salários são baixos, mesmo quando mais pessoas na família trabalham ou auferem alguma renda (como o irmão inválido de um dos respondentes) e se situavam entre $R \$ 400,00$ a $R \$ 660,00$.

No centro, a idade dos respondentes variava entre 20 e 23 anos. Três dos entrevistados nasceram em Luziânia e dois em Taguatinga, no DF. Todos possuíam o $2^{\circ} \mathrm{grau}$ completo, dois cursavam uma faculdade particular local, a FIPLAC (Faculdades Integradas do Planalto Central), e um terceiro se preparava para o vestibular em uma universidade privada do DF. A renda familiar se situava entre $R \$ 1.800$ e $R \$ 4.000$ e três dos entrevistados trabalhavam.

As entrevistas, realizadas sob a forma de debate com a participação de todos, duraram, aproximadamente, uma hora e meia cada. Gravadas e transcritas, pôde-se identificar os núcleos de sentido da identidade, da violência, do comportamento e das relações entre a periferia e o centro da cidade.

Luziânia era "pacata", como a definiu COELHO (1989, p.13), cujo centro reunia as casas e igrejas em estilo barroco, comércio de pequeno porte e meios de transporte primitivos. O ritmo colonial do município e sua organização territorial, ressalta TORMIN (2004), foi revolucionado com a construção da nova Capital da República.
O alto preço da terra no Distrito Federal redirecionou os intensos fluxos migratórios que à demandavam a Brasília para os municípios vizinhos e Luziânia experimentou grande crescimento demográfico. A população passou de 23.247 habitantes em 1960 para 32.800 em 1970, 94.219 em 1980, saltando para 207.674 em 1991. A criação de novos municípios (Santo António do Descoberto, Cidade Ocidental, Valparaíso de Goiás e Novo Gama) reduziu temporariamente o número de habitantes e o Censo de 2000 apurou 141.042 habitantes. Em três anos, porém, ocorreu novo aumento e, segundo a estimativa de 2004 do IBGE, residem na área 160.330 pessoas. Capturada na modernização espacial ocasionada pela implantação de Brasília, Luziânia foi transformada em mais um dos municípios do "Entorno" do Distrito Federal ${ }^{1}$, no qual os loteamentos de baixa renda, violentos e sem infra-estrutura, se expandem, cercando o centro tradicional.

Nesse contexto, os objetivos que se pretende atingir são dois. O primeiro é verificar como o fato de pertencer a um grupo religioso influencia as visões de mundo e de si mesmo dos jovens moradores da periferia, que terminam por ocasionar as mudanças de identidade e comportamento. O segundo é refletir como a falta de emprego e de infra-estrutura, além da exclusão social, contribuem para a construção de um imaginário social que penaliza os jovens pobres e periferizados.

Para atingir esses objetivos, três hipóteses nortearam o trabalho: de acordo com a primeira, ao se modernizar um espaço, como ocorreu em Luziânia sob a influência de Brasília, criam-se territórios degradados de pobreza e exclusão, cujos moradores são percebidos como possuidores de identidades deterioradas. $\mathrm{Na}$ segunda hipótese, considera-se que, nos espaços periféricos, os processos de mudanças espaciais pelos quais passaram seus moradores tornam fluídas as normas de conduta anteriormente aceitas e a pobreza e exclusão fornecem regras e valores, em que a violência e a criminalidade são uma constante. Na terceira 
hipótese, pertencer a um movimento religioso, no caso da Igreja Católica, resgata o sujeito, permite o surgimento de novas sociabilidades, valores e identidades, o que leva a mudanças de comportamento.

Deve-se ressaltar três aspectos. O primeiro deles é que não se vai fazer um trabalho sobre religião, mas procura-se entender o movimento religioso como mediação da mudança entre uma determinada identidade e um determinado comportamento e outra identidade e outro comportamento. Assim, a religião atravessa o discurso dos jovens e estabelece os parâmetros para que cada um fale de si próprio, dos outros e do mundo. O segundo é que não se vai trabalhar com dados quantitativos, mas qualitativos, em que poucos entrevistados permitem conhecer fatos e fenômenos bastante gerais, pois cada um condensa em si a totalidade, no momento em que "o singular materializa o geral" (CIAMPA, 1994, p. 126). As falas, portanto, se completam para enunciar a totalidade. O terceiro é que as análises dos discursos vão se referir continuamente ao contexto cotidiano dos jovens respondentes, no qual tomam corpo as experiências vividas de violência, identidade, comportamento, centro e periferia, ou seja, as condições objetivas de vida estarão sempre presentes. Dessa maneira, se talvez os resultados obtidos não possam ser generalizáveis, considera-se que são importantes para a compreensão da violência nas periferias brasileiras.

O presente trabalho se divide em 4 partes. $\mathrm{Na}$ primeira parte, o fio condutor será a primeira hipótese e vai-se mostrar como se forma a identidade deteriorada dos moradores da periferia. Na segunda parte, com a segunda hipótese como fio condutor, o enfoque será sobre os processos migratórios, durante os quais os valores e as normas de origem rural são dissolvidas e substituídas por normas e valores urbanos. Na terceira parte, tendo como referência a terceira hipótese, apresenta-se a transformação da identidade e dos comportamentos dos jovens com o ingresso no movimento religioso da Igreja Católica. $\mathrm{Na}$ última parte, finalmente, as conclusões, sublinhando a historicidade das identidades.

\section{II- Exlusão, identidade e violência na periferia de Brasília e Luziânia}

Escreve CLAVAL (2001, p. 39) que "as relações dos homens com o meio ambiente e com o espaço têm uma dimensão psicológica e sociopsicológica", cujas implicações se procurou resgatar nas entrevistas com os jovens de Luziânia. A análise dos discursos revelou um material extremamente diversificado e rico, cujas dimensões psicológicas, sociopsicológicas e espaciais já haviam sido analisadas anteriormente sob o enfoque de representações sociais da violência ${ }^{2}$.

A raiz, ou núcleo central, das representações sociais dos entrevistados, a partir da qual se formou a realidade simbólica que estrutura a compreensão da violência entre os jovens de Luziânia, se dispõe segundo três linhas básicas. As duas primeiras estão juntas como o verso e o anverso de uma moeda: num dos lados, a inclinação para o mal, visto como uma potência avassaladora, e a má formação das pessoas são os detonadores da violência e, no outro lado, a revolta, a inveja e o sentimento de inferioridade dos pobres por não poderem ter aquilo que desejam. A terceira linha localiza a potência, a má formação, a inveja e o sentimento de inferioridade nos territórios de pobreza e exclusão da periferia de Luziânia.

A violência, segundo as representações sociais elaboradas pelos entrevistados, é um ato que começa dentro da pessoa, extravaza e atinge o que está fora. Começa com a revolta e a confusão de não ter o que se precisa ou se deseja, enquanto a baixa qualidade de vida e a pobreza são entendidas como o empurrão para o ingresso do jovem no mundo do crime. O assalto chega a ser, de certa forma, justificado como necessidade decorrente da revolta de não possuir os bens desejados e de ser 
incompreendido por interlocutores distantes e hostis que mandam os pedintes buscar emprego num mundo em que a habilitação dos pobres não Ihes faculta um trabalho. O estereótipo do menino faminto que rouba para atender suas necessidades e as da família, que ZALUAR (1996, p. 97) aponta como "o modelo explicativo para o pandemônio instalado nas cidades brasileiras", toma forma no imaginário dos jovens tanto da periferia como do centro.

Entretanto, como assinala WOODWARD, a representação inclui as práticas de significação e os sistemas simbólicos por meio dos quais os significados são produzidos, posicionando-nos como sujeitos. É por meio dos significados construídos pelas representações que damos sentido à nossa experiência e àquilo que somos (WOODWARD, 2000, p. 17),

As representações sociais estariam, portanto, no cerne do processo de formação e afirmação das identidades sociais, baseadas num imaginário que cria e alimenta a concepção e a interpretação que se faz das coisas. (TORMIN, 2004). Trata-se do registro psicossocial, ao qual CLAVAL (2001, p. 40) atribui a construção da "identidade por meio do sentido dado às coletividades".

Uma questão central na formação identitária das coletividades moradoras onde o acesso ao que LEFEBVRE (1991, p.115) chama de "direitos à vida urbana" - instrução, educação, trabalho, cultura, repouso, saúde, habitação - é escasso, é a auto-estima dos moradores, que é baixa pela avaliação do baixo status da cidade. Os problemas sociais, tais como violência e criminalidade, e problemas urbanos, como falta de infra-estrutura, são atributos espaciais que estigmatizam os moradores. A identidade social, portanto, é negativa. Para GOFFMAN (1988, p. 12-13), o estigma é "um tipo especial de relação entre atributo e estereótipo". Certos atributos, escreve ele, estigmatizam uma pessoa, posicionando-a em desvantagem em relação aos outros, tornandoa diferente, menos desejável e, "num caso extremo, uma pessoa completamente má, perigosa ou fraca. Assim, deixamos de considerá-la criatura comum e total, reduzindoa a uma pessoa estragada e diminuída".

Os atributos negativos das coletividades periféricas que constam das representações sociais criadas pelos jovens entrevistados têm no migrante a figura central. A pergunta "quem é o migrante?" mostra "a articulação da diferença e da igualdade" (CIAMPA, 1994, p. 138) que leva a duas outras perguntas: para os moradores da periferia a nova interrogação é "quem sou eu?", enquanto para os moradores do centro é "quem são eles?". Na figura do "migrante" se estabelecem alteridades em que as relações sociais expressas na forma urbana "periferia" instituem o si mesmo e os outros em contínuas oposições pelas quais os grupos se reconhecem, atribuem-se e conquistam papéis, "status", reconhecimento e auto-estima. É o que se poderia chamar de "economia da identidade e do espaço urbano" (PELUSO, 1997, p. 1097).

A pergunta "quem é o migrante" encontra, entre os entrevistados do Jardim Ingá, respostas que delineiam os atributos de quem sai de sua terra. O primeiro atributo do migrante é o nomadismo. Os pais dos respondentes migraram tantas vezes que perderam a conta e os irmãos estão dispersos. Cada um dos jovens já se mudou inúmeras vezes entre o Distrito Federal e a periferia, entre os loteamentos da própria periferia, entre Luziânia e os lugares de origem ou mesmo outros.

Um jovem diz: "são metade nômades". Se uma metade não tem repouso, a outra metade aspira ao sedentarismo, mas nem mesmo a propriedade de um imóvel, como as casas que possuem no Jardim Ingá, garante-lhes a estabilidade, porque a falta de emprego pode fazê-los mudar novamente. O nomadismo desses jovens e de suas famílias é ligado à miséria de ser de um lugar que não oferece qualidade de vida e chegar a outro que não oferece grandes oportunidades. O migrante, então, tem como atributos, a pobreza e a desilusão. 
Dois depoimentos sintetizam bem o movimento espacial que repõe a pobreza sem superá-la. No lugar de origem há a miséria: é que no interior as pessoas são muito miseráveis, afirma um dos entrevistados e outro completa: aí as pessoas vêm e aqui não é como elas pensavam. Pensam que aqui a gente fica rico.

No centro de Luziânia, os pais de três dos jovens entrevistados também vieram de outros estados, mas, apesar de considerá-los migrantes que vieram em busca de uma vida melhor, seus atributos são positivos. Em primeiro lugar, há a possibilidade de escolha do lugar onde morar como diz esse entrevistado, para quem ficar em Luziânia significa fugir do corre-corre da cidade grande. Então, em vez de ir para Brasília, fica em Luziânia, que é próximo e tem o conforto de uma cidade pequena. Os migrantes pobres não têm escolha, porque queriam ficar no $D F$, mas, por algum motivo não conseguem e vêm para cá.

Em segundo lugar, os migrantes do centro têm emprego fixo, os pais trabalham e os filhos não só estudam, como exercem diversas ocupações em Luziânia. Em terceiro lugar, os migrantes por opção possuem estabilidade: meus pais moram tanto tempo aqui, 34 anos, que já se consideram daqui, responde esse jovem.

E, por se considerarem de Luziânia, adotam o discurso das elites do lugar, pois passaram a pertencer a elas. Os atributos negativos dos migrantes não só se localizam na periferia, como têm, como parâmetro, os migrantes bem sucedidos. Assim, de acordo com os jovens do centro, o morador da periferia apresenta mais três atributos negativos, além daqueles que os próprios periferizados já haviam listado.

Primeiro, o migrante é um fracassado: o cara vem de outro estado, constitui uma família e, de repente, ele não tem dinheiro para sustentar a família; ele sai e não consegue trabalho. Segundo, trás consigo a violência, porque o número dos que chegam é excessivo e tende a aumentar e, quando vai aumentado o número de pessoas, a chance de ocorrer a violência é maior, pondera um respondente. Em terceiro lugar, o migrante é o que invade o espaço do outro, não só da elite, como dos outros pobres, privandoos de oportunidades de trabalho e bem-estar. Para este entrevistado, os ricos perdem com a migração, pois muitos recursos que eram para ser dos filhos das famílias tradicionais de Luziânia, acabam indo para os migrantes.

Mas os pobres também são penalizados pelos outros pobres. E o respondente continua, referindo-se agora ao anverso da moeda:

Eles tomaram conta de tudo. Está acabando o emprego por causa dessa migração. O jovem então, por não ter emprego e, digamos, chegar em casa e são tão pobres, tão de baixa renda a família, que não tem o que comer e aí vai roubar, vai traficar.

Ao responder a "quem são eles", a identidade deteriorada atribuída aos migrantes pobres corresponde bem ao que CIAMPA (1994, p. 179) denomina de identidade-mito, com a qual se esconde o caráter social e político da migração e da pobreza, tirando-as da esfera das relações sociais e jogando-as para a esfera do comportamento individual. Nesse tipo de discurso, as contradições econômicas e sociais permanecem ocultas e naturalizadas. Este é o segredo da identidade-mito (CIAMPA, 1994, p. 179). Assim, o centro e a periferia assumem o discurso das elites, segundo o qual a violência passa a ser culpa dos pobres, os migrantes são responsáveis por suas carências, pois são pessoas perigosas e diminuídas.

\section{III- Nomadismo, identidade e violência}

As identidades podem ser entendidas como o resultado de um processo histórico que condensa as relações sociais e as dimensões psicológica. Como coloca CIAMPA:

Cada indivíduo encarna as relações sociais, configurando uma identidade pessoal. (...) Uma identidade concretiza uma política, dá corpo a uma ideologia. No seu conjunto, as 
identidades constituem a sociedade, ao mesmo tempo que são constituídas cada uma por ela." (CIAMPA, 1994, p. 127)

As relações sociais que organizaram a dimensão psicológica do centro e da periferia estão objetivadas na resposta à pergunta "quem sou eu?". Os jovens do centro e da periferia se reconhecem como filhos de migrantes, que deixaram suas cidades natais em busca de melhores oportunidades. No centro, porém, além das mudanças de residência terem sido poucas (ou percebidas como poucas, por isso não são mencionadas), Luziânia é vista como um lugar de oportunidades e de trabalho, de vida familiar e de estabilidade, tanto por aqueles cujos pais são do lugar quanto pelos que migraram. Um respondente explica porque o pai permaneceu na cidade: acho que é porque toda a família mora aqui, ele tem muitas oportunidades, então ele tem mais estabilidade, assim...

Os pais migrantes dos outros dois jovens sentem-se bem no lugar, de maneira que, no centro, os laços sociais que se haviam desfeito durante a migração se reconstituem e a mobilidade espacial levou à integração na vida da cidade. Os pais migraram em busca de melhores oportunidades e as encontraram, os filhos se integraram igualmente e se consideram do lugar. Eles constroem, então, suas identidades sociais e territoriais "dentro de uma relação de apropriação que se dá tanto no campo das idéias quanto no da realidade concreta" (HAESBAERT,1999, p. 172).

$\mathrm{Na}$ periferia os próprios jovens se consideram também migrantes, pois se deslocaram muitas vezes com seus pais, ou mesmo sozinhos, até encontrar o atual período de sedentarismo no Jardim Ingá. Os respondentes, porém, encontram dificuldades em se apropriar de um lugar que, em sua própria avaliação, hoje não tem jeito e onde falta tudo e que pode ser abandonado por outros lugares com melhores oportunidades.

Assim, na periferia, ser migrante é uma vivência continuada de mobilidade espacial e psicológica, em que a ascensão e a integração sociais estão continuamente se desfazendo e se refazendo. O nomadismo é visto como maneira de melhorar a qualidade de vida da família, e todos acham que melhorou um pouco. A passagem de uma vida rural, na qual a fome era uma ameaça constante, para uma vida urbana em que há possibilidade de emprego e alimentação é uma grande ascensão, mesmo não ultrapassando os limites de mudança social que os coloca e recoloca continuamente como pobres.

Mas, como há sempre a possibilidade de perder o pouco que se conseguiu, as melhorias nunca estão seguras. Na periferia, a ascensão social não é garantida e sempre é possível uma regressão. Esse respondente lamenta a separação dos pais, da qual resultou uma queda no status social e econômico da família pela divisão dos bens escassos:

Eu me lembro, em criança, que meu pai chegou a ter uma Kombi, construiu a casa da gente. Comparar as condições...tudo podia ter sido muito bom.

Os pais podem se separar; os empregos podem ser perdidos e as famílias se dispersarem, como os irmãos de um dos entrevistados, que saíram do Entorno em busca de trabalho em outros lugares; os irmãos podem se desentender, brigar, matarem-se. Nada é seguro, estável, confiável. As constantes desterritorializações e reterritorializações vão deixando para trás a sensação de pertencimento, de durabilidade, de integração e de estabilidade.

O Jardim Ingá é, então, visto como um lugar fracionado e caótico, sem infra-estruturas, sem emprego, desintegrado, violento, sem normas de conduta aceitáveis: violência nas famílias, as pessoas se matando, se suicidando, caras matando colegas de escola, diz um dos entrevistados. É preciso ter relações mais estáveis, completa outro. Eles moram num lugar excluído por Luziânia, cujos políticos nunca cumprem o que prometem e que se tornou o 
lugar de despejo do que não funciona em Brasília. Um dos respondentes testemunha:

O Distrito Federal exclui o Entorno. Por exemplo, o Distrito Federal implanta um projeto de tolerância zero, os marginais vêm tudo para cá. Então sempre eu ouço falar nisso na região "Olha, teve uma fuga em Brasília, fugiram da polícia não sei onde" e vêm tudo para cá.

A idéia de fracionamento e caos vai-se articulando com a busca de solução, na qual se interpenetram a falta de estrutura social, a falta de estrutura pessoal de pais e filhos, a falta de estrutura espacial, como explica esse jovem:

De repente pegar os bairros assim, mais humildes, onde a violência é bem maior, e estruturar mesmo. Falta trabalho para os jovens porque é falta de estrutura mesmo. É preciso capacitar a educação dos pais. A questão está voltada para ali, para a infraestrutura.

Não há, portanto, como apropriar-se de um território com significados tão conturbados e construir uma identidade social positiva. Nessas condições, o sujeito procura ancorar-se num território mítificado, em que era possível a amizade, a camaradagem, a estabilidade, o respeito pelos outros e por si mesmo - a terra natal. Então, o lugar empobrecido, sem condições materiais de vida se transforma em seu oposto. O jovem da periferia procura evitar a falta de um centro identitário social, espacial e pessoal como a periferia e volta-se para o passado, ao lugar de origem ressignificado, onde as pessoas conversam, brincam.

Esses "novos nômades", objetos de "grandes diásporas migrantes", como os define HAESBAERT (1999, p. 170), atribuem à sua terra natal o que não encontram na periferia urbana de Brasília e de Luziânia e retomam uma memória partilhada por pais que contam e filhos que escutam:

$\mathrm{Na}$ área rural eles vivem num ambiente de partilha. Apesar de viverem mais longe uns dos outros, lá eles partilham mais. Partilham o leite, partilham o arroz. O pouco que tem, eles partilham. Ninguém passa fome.
Ao contrário do mundo coletivo e integrado da área rural, na cidade predomina "a ideologia individualista moderna" que enfraqueceu os laços de lealdade entre as pessoas e enfraqueceu também "seu correspondente mapa de valores ou de símbolos" (ZALUAR,1996, p. 109). No mundo rural de origem, o indivíduo estava ligado à estrutura social e a identidade era formada " 'na interação' entre o eu e a sociedade" (HALL, 1997, p. 12), o que deixou de acontecer durante as migrações. O mundo estabilizado de identificação mudou, perdeu-se no tempo mítico do passado e o sujeito se sente fragmentado e sozinho.

A violência se torna, então, uma causa do isolamento e uma conseqüência, e os moradores da periferia não se reconhecem mais como pessoas. O entrevistado continua seu discurso:

Aqui na cidade a gente vê muito isso. As pessoas estão muito isoladas, muitas vezes passando necessidade, a criança, na mesma rua e ninguém ajuda. Falta união mesmo. Isso ajuda a violência na cidade, exatamente as pessoas se fecham, as pessoas ficam com medo de confiarem umas nas outras por causa da violência. Eles se fecham, não querem mais conhecer os vizinhos.

A periferia de moradores solitários, desestruturados e sem capacitação, que procuram proteger-se da violência, isolando-se uns dos outros, torna-se o ambiente propício para desenvolver a inclinação para o mal, para sentir inveja e inferioridade, porque desejam a amizade e a união que lhes é negada.

A Igreja Católica aparece, então, como - lugar que pode transforma-los, que vai permitir-lhes reconstruir suas identidades como algo positivo e valorizado. 


\section{IV- O encontro com a igreja e o resgate do sujeito}

A periferia interpela continuamente os sujeitos. Para o jovem morador da área central, seu espaço na cidade nunca está a salvo, porque os moradores violentos dos loteamentos não ficam confinados aos seus lugares. O encontro conflituoso entre centro e periferia se dá a todo momento, mas principalmente nos fins de semana, porque o pessoal desce. A periferia vem para o centro de Luziânia. E a periferia assalta, comete crimes, trafica, consome drogas e álcool, aterroriza a todos, toma conta das ruas e impede o movimento das pessoas. Os jovens ficam restritos às casas dos pais e amigos, a calma da cidade pequena desaparece porque os marginais interditam as ruas e, assim, em vez de sair, a gente vai a festas reservadas na casa de amigos bons ou na nossa própria casa.

Nessas condições é importante sentir-se seguro física e psicologicamente e estabelecer uma diferença firme entre quem é bom e quem não é, porque não é só o presente que interpela os jovens do centro, mas também o passado. Os entrevistados sentem a perda de valores e normas que deixavam as pessoas confiáveis, como atesta esta exaltação da honestidade passada, em contraposição ao que ocorre no presente. Nas palavras de um entrevistado:

Antigamente, a palavra do homem valia muito mais do que a assinatura hoje. Hoje em dia, um contrato que era assinado, naquela época era um aperto de mão. A palavra era realmente cumprida e hoje em dia você vai ver, confiar na palavra de quem?

O jovem de Luziânia percebe, então, que pertencer à Igreja Católica permite-lhe ficar do lado dos bons. TORMIN (2004) mostra a importância da religião católica na tradição da cidade desde seus primórdios coloniais, seja na determinação dos valores morais, das atividades culturais e dos costumes. Pertencer à Igreja Católica é, então, ancorar-se num passado profano mitificado que produz normas e valores perenes, e internalizá-los e segui-los proporcionam pertencimento a alguma coisa maior do que eles mesmos. Perguntados sobre os motivos pelos quais haviam aderido ao grupo de jovens, a resposta mostra a importância de estarem entre pessoas conhecidas e entre familiares e, junto com eles, afirmar os valores morais do grupo. Num mundo em que não se pode confiar em ninguém, em que a criminalidade ronda a todos, eles estão com um grupo de pessoas honestas, pessoas conhecidas, pessoas que sentem que estão fazendo o bem, procurando ajudar outras pessoas também.

As atividades do grupo permitem a amizade e a união entre seus membros que vão se construindo em encontros para atividades culturais, para a oração e para o lazer, pois é uma coisa que você tem encontros, tem confraternizações, envolvem toda a família, pai, mãe, irmãos. Então, pertencer ao grupo de jovens marca uma diferença de costumes, assumindo-se que os jovens de fora do grupo apresentam moral e costumes duvidosos. Freqüentar a Igreja é importante porque, sendo assim, não se sente falta de fazer o que os outros jovens fazem, não sente falta de fazer o que eles estão fazendo.

Os jovens pertencem não só a um grupo religioso, mas a um grupo tradicional e conhecido na cidade, no qual todos se conhecem e que permite o reconhecimento de si: eu trabalhei com a irmã dele, com os amigos dele. 0 conhecimento da comunidade lhes permite interagir socialmente e instituir uma identidade estável e temporalmente contínua, que vem de um passado, mantém-se no presente e aponta para um futuro. O caos e a desordem se encontram na cidade invadida pela periferia, mas em seus redutos os moradores de Luziânia centro constróem uma identidade positiva para si mesmos e escapam da moral e dos costumes duvidosos dos outros jovens. Não há verdadeiramente mudança de comportamento, mas afirmação e reafirmação de um comportamento correto.

Assim estabelecidos e ancorados estavelmente no mundo social (HALL, 1997, p. 
7), os jovens desempenham um papel evangelizador para resgatar os outros jovens do mundo da criminalidade e da violência:

A gente está aqui nesse encontro procurando tirar os jovens da violência, com palestras, com encontros. Nosso trabalho é fazer com que os jovens violentos busquem a Igreja, que é a saída mais certa para não entrar no mundo da violência.

$\mathrm{Na}$ periferia, desconstruídos e descentrados, depois de um longo processo de fragmentações, pertencer ao grupo de jovens significa mais uma ruptura, desta vez com o comportamento violento motivado pela má potência, má formação, revolta e inferioridade. Há um tempo do antes, quando o jovem se sente só como possuidor de uma identidade degradada em companhia dos maus e perigosos. Então ele toma uma decisão de mudar e o "quando" estabelece a temporalidade da ruptura em busca da integração do eu com o novo grupo:

Quando eu decidi participar de um grupo de jovens, eu era revoltado. Eu saí queria nem saber, preferia ficar sozinho, vivia com gente violenta, metida com droga, gente desestruturada. Muitos morreram por causa da droga, outros foram presos. Eu saí por causa do grupo de jovens, por causa da amizade de muitos aqui.

O jovem da periferia vai encontrando "um sentido estável de si" (Hall, 1997, p. 9) ao encontrar as pessoas boas que freqüentam o grupo de jovens, que lhe permite conhecer outras realidades nas quais pode encontrar uma posição prestigiada e ancorar uma identidade estável. Supera-se a identidade deteriorada pelo conhecimento/reconhecimento de outras pessoas, o que lhe possibilita abrirse para o outro, pois foi uma chave, assim, o conhecimento. Conhecer pessoas não só daqui, mas também de outros lugares, outros grupos.

Ligar-se ao grupo de jovens permite ao indivíduo estigmatizado mostrar que, em sua "carreira moral", na expressão de GOFFMAN
(1988, p. 41), incorporou referenciais diferentes daqueles que o cercam. O entrevistado incorpora uma identidade positiva e desestigmatiza-se, pois já não possui aquele estigma particular, a falta de moral, a violência, o consumo de drogas e de álcool que faziam parte de sua vida pregressa. Ele está agora livre dos atributos do marginal.

Entretanto, a mudança não se faz facilmente. Todos reconhecem que foram muitas as idas e as vindas, o aproximar-se e o afastarse, se bem que as famílias também estivessem envolvidas nas diversas atividades evangelizadoras da igreja. Na periferia, porém, ao contrário do centro, as famílias não significam a continuidade de uma tradição antiga e aceita, mas são o testemunho vivo do mito do migrante que nada possuía e pouco alcançou em sua vida de nomadismo e de trabalho.

Portanto, se é a família que indica o caminho, segui-lo depende da experiência pessoal. Na história desse jovem, entrar no trabalho da igreja envolveu o reconhecimento de seu desamparo e estigma, no qual o teatro desempenhou um papel crucial. O grupo de jovens do Jardim Ingá encena a Via Sacra, na Semana Santa, assim como outras peças de teatro e inclusive realiza oficinas de gestualidade, sensibilização e postura para os artistas amadores. "Numa das peças, que falava sobre um jovem mendigo deficiente físico, e nosso colega participou. $\mathrm{E}$ ele falava que todos eram maus para ele, ninguém gostava dele e deu essa conotação de que ele estava sozinho também e o papel de mendigo deficiente... meu coração de jovem era um coração deficiente e mendigo também. Então eu me vi naquela interpretação teatral e naquele grupo me senti acolhido e ai estou até hoje no Grupo Jovem."

A identificação com o mendigo solitário foi o encontro consigo mesmo, a catarse necessária para que se pudesse gestar nova identidade na igualdade, compartilhando novos interesses e valores, e na diferença, rejeitando os valores e os comportamentos do mundo. Completa-se, assim, a dialética entre a boa e a 
má identidade e o jovem, redimido, torna-se um evangelizador que procura ensinar para 0 adolescente o que é bom, o que é ruim.

O jovem, no movimento evangelizador, já não se considera mais pertencente ao grupo de risco de violência. Ocorreu nova ruptura em sua vida e a nova identidade daí advinda tem como trabalho agir para que outros jovens também se transformem. O trabalho agora é trazê-los do mundo para cá, para mudar seu modo de pensar e de agir.

Mas a periferia volta a interpelar o sujeito transmutado. Evidentemente, festas e eventos procuram atrair os jovens que estão no mundo, mas a descoberta da realidade não se faz na festa e sim no encontro com os atributos negativos que constituem os espaços excluídos - os orfanatos, os asilos -, representantes de tragédias que poderão engolfá-los no futuro:

Nunca tinha ido num orfanato na minha vida, conheci a realidade do que é ser uma criança carente de verdade, pegar no colo, me chamar de tio, de conhecer a realidade do asilo e saber que um dia eu posso parar num asilo também. Alguns de nós podem parar num asilo.

Nesses novos espaços de exclusão e de pobreza, os jovens novamente se reconhecem como aqueles cujo périplo pelo espaço nacional e sedentarização no Jardim Ingá criaram as condições para repor o mesmo - identidades deslocadas e carentes.

\section{V- Como conclusão: a reprodução das identidades}

Um estudo sobre identidade levanta as contradições das construções simbólicas entre centro e periferia nas cidades brasileiras, que estão em relação com as realidades que instituem os pobres, os excluídos e os marginais, mas também as possibilidades de fuga de suas condições de existência. Afinal, a identidade é um fruto social/cultural/histórico, como observa Jonathan Rutherford, citado por WOODWARD, e pressupõe relações de poder:
(...) a identidade marca o encontro de nosso passado com as relações sociais, culturais e econômicas nas quais vivemos agora (...) a identidade é a intersecção de nossas vidas cotidianas com as relações econômicas e políticas de subordinação e dominação" (Rutherford apud Woodward, 2000, p.19).

As identidades, como ressalta JOVCHELOVITCH (2000, p. 192), para as representações sociais "emergem das relações sociais e, ao dar a estas relações sentido, carga afetiva e modo de expressão, elas permitem aos sujeitos sociais ordenar, apresentar motivos e desejar realidades alternativas". Ambos os grupos de jovens atribuem os problemas de violência e suas causas à sociedade, mas crêem, também, que só a Igreja salva - ficar próximo a Deus, nas Igrejas - , porque só a partir de seus ensinamentos emerge o certo e o errado e a possibilidade de mudança nos comportamentos. Com a religião, o indivíduo está de posse de uma nova maneira de ver o mundo, que redifine sua vivência e seu comportamento e lhe dá a possibilidade de redifinir a vivência e o comportamento dos outros.

Ou seja, mesmo que problemas de violência estejam na esfera mais ampla da sociedade, as soluções encontram-se na esfera individual. É o jovem, em situação de risco, de violência e marginalidade, que muda numa sociedade que permanece a mesma, fornecendo todas as condições para que a criminalidade se reproduza nas periferias excluídas e excludentes. Dessa maneira, as contradições sociais e econômicas são corporificadas no sujeito culpabilizado: ele é mal formado, revoltado, invejoso e inferiorizado e deseja o que não tem. A religião o salva e lhe fornece o caminho para a transmutação individual. Assim, as contradições permanecem na esfera do sujeito, sem que ocorra sua projeção para a esfera social. Esse é o jogo invisível da reprodução das relações sociais, das representações e das identidades, tanto as da periferia quanto as do centro. 


\section{Notas}

${ }^{1}$ A expressão "Entorno do Distrito Federal" se refere aos municípios limítrofes do DF e ganhou seus contornos definitivos em 1975, com o Programa Especial da Região Geoeconômica de Brasília, para distinguir os municípios mais próximos dos mais distantes.
2 Trata-se do artigo "Violência, contradições espaciais e representações sociais em Luziânia, no Entorno de Brasília/DF", das mesmas autoras, a ser publicado em FERREIRA, I.C.B.; PAVIANI, A.; BARRETO, F.F. .Violência urbana em Brasília e Entorno. Brasília: Editora UnB, no prelo.

\section{Bibliografia}

CIAMPA, Antônio da Costa. A estória do Severino e a história da Severina. Um ensaio de Psicologia Social. São Paulo: Editora Brasiliense, 1994, 242 p..

CLAVAL, Paul. O papel da nova Geografia Cultural na compreensão da ação humana. In ROSENDHAL, Zeni; CORRÊA, Roberto Lobato. Matrizes da Geografia Cultural. Rio de Janeiro: UFRL, 2001, p. 86.

COELHO, Wilter Campos. Eternamente Luziânia. Luziânia: HP Mendes Gráfica. 1989, 89 p..

GOFFMAN, Irving. Estigma. Notas sobre a manipulação da identidade deteriorada. Rio de Janeiro: Editora Guanabara Koogan, 1988, 158 p..

HAESBAERT, Rogério. Identidades territoriais. In ROSENDAHL, Zeny; CORREAA, Roberto Lobato. Maifestações da cultura no espaço. Rio de Janeiro: Editora UFRJ, p. 169-190.

HALL, Stuart. Identidades culturais na pósmodernidade. Rio de Janeiro: DP\&A Editora, 1997, 92 p..
INSTITUTO BRASILEIRO DE GEOGRAFIA E ESTATÍSTICA. Censos Demográficos. 1960, 1970, 1980, 1991, 2000.

- Contagem da população de 2004

LEFEBVRE, Henri. O direito à cidade. São Paulo: Editora Moraes, 1991, 145 p..

TORMIN, Cassiana Vaz. Um lugar e suas raízes. O pensamento político em Luziânia/GO. Dissertação de Mestrado. Programa de Mestrado em Geografia. Departamento de Geografia, Instituto de Ciências Humanas, Universidade de Brasília, Brasília, 2004, mímeo, 140 p..

PELUSO, Marília Luiza. O indivíduo como sujeito de territorialidades coletivas. 7a Encontro Nacional da ANPUR, Anais. Recife: 1997, v. 2, p. 1090-1115.

WOODWARD, Kathryn. Identidade e diferença: uma introdução teórica e conceitual. In SILVA, Tomas Tadeu da (org.). Identidade e Diferença: a Perspectiva dos Estudos Culturais. Petrópolis/ RJ: Vozes, 2000, p. 5-25.

ZALUAR, Alba. Da revolta ao crime S. A. São Paulo: Moderna, 1996, 128 p.. 
